UDC: $616.127-005.8-083.98$

Ivanović V, i sar. Kasni STEMI prezenteri. Halo 194. 2020; 26(3):119125.

Rad primljen: 14.07 .2020

Prihvaćen: $\quad 02.12 .2020$.

\section{Korespodencija:}

Vladimir Ivanović Klinika za kardiologiju Institut za kardiovaskularne bolesti Vojvodine

Put dr Goldmana 4

21204 Sremska Kamenica Srbija

Tel.: +381214805773

E-mail:

vladimir.ivanovic@mf.uns.ac.rs
ORIGINALNI RAD

\section{ISHOD LEČENJA U ODNOSU NA TRETMAN BOLESNIKA SA AKUTNIM ST ELEVIRANIM INFARKTOM MIOKARDA KOD KOJIH JE OD POČETKA TEGOBA PROŠLO VIŠE OD 12 A MANJE OD 48 SATI}

\author{
Vladimir IVANOVIC' ${ }^{1,2}$, Jelena GRGUR ${ }^{3}$, Dragana DABOVIĆ ${ }^{1}$, Milovan \\ PETROVIĆ ${ }^{1,2}$, Anastazija STOJŠIĆ-MILOSAVLJEVIĆ ${ }^{1,2}$, Marija BJELOBRK ${ }^{1,2}$, \\ Milenko ČANKOVIĆ ${ }^{1,2}$, Maja STEVANOVIĆ ${ }^{1,2}$
}

${ }^{1}$ Institut za kardiovaskularne bolesti Vojvodine, Klinika za kardiologiju, Sremska Kamenica, Srbija; ${ }^{2}$ Univerzitet u Novom Sadu, Medicinski fakultet, Novi Sad, Srbija;

${ }^{3}$ Institut za zdravstvenu zaštitu dece i omladine Vojvodine, Novi Sad, Srbija.

\begin{abstract}
SAŽETAK
Uvod/cilj Pacijenti kod kojih je prema anamnestičkim podacima, prošlo više od $12 \mathrm{~h}$ od početka tegoba, se smatraju kasnim prezenterima akutnog infarkta miokarda. Podaci o tretmanu ovih pacijenata u literaturi su oskudni i često kontroverzni. Cilj rada je bio prikazati ishod lečenja pacijenata sa akutnim infarktom miokarda sa elevacijom ST segmenta (STEMI) kod kojih je od početka tegoba prošlo više od $12 \mathrm{~h}$, a manje od $48 \mathrm{~h}$ u odnosu na lečenje.

Metod rada U istraživanje je uključeno 130 STEMI pacijenata, kod kojih je od početka tegoba prošlo više od $12 \mathrm{~h}$, a manje od $48 \mathrm{~h}$, koji su u periodu od januara do decembra 2017. godine lečeni u Institutu za kardiovaskularne bolesti Vojvodine. Od ukupnog broja, je 109 pacijenata lečeno primarnom perkutanom koronarnom intervencijom (pPCI), a 21 pacijent konzervativno. Potom je izvršena korelacija između ishoda lečenja, intrahospitalnog mortaliteta, jednogodišnjeg preživljavanja u odnosu na tretman, kao i faktore rizika i komorbiditete.

Rezultati Verifikovana je statistički značajna razlika $\left(\mathrm{x}^{2}=7,119 ; \mathrm{p}=0,017\right)$ u mortalitetu STEMI pacijenta lečenih pPCI $(8,3 \%)$ i konzervativno $(28,6 \%)$. Rezultati naše studije pokazali su, da starost, hereditet, hiperlipoproteinemija, dijabetes mellitus i pušenje, statistički značajno utiču na ishod lečenja. Pol, hipertenzija i ejekciona frakcija leve komore, nisu postigli nivo statističke značajnosti u odnosu na ishod lečenja. Ni jedan komorbiditet nije pokazao statistički značajnu razliku u distribuciji, u odnosu na tretman i ishod lečenja.

Zaključak Prilikom donošenja odluke o lečenju ovih bolesnika trebalo bi uzeti u obzir kliničku sliku, hemodinamski status i prisustvo životno ugrožavajućih aritmija. Jasnih preporuka o tretmanu ovih bolesnika još uvek nema.
\end{abstract}

Ključne reči Akutni infarkt miokarda, primarna perkutana koronarna intervencija, medikamentni tretman, ishod.

\section{UVOD}

Akutni infarkt miokarda je glavni uzrok morbiditeta i mortaliteta u svetu. Prema statističkim podacima, na globalnom nivou se godišnje registruje više od tri miliona ljudi, sa dijagnozom akutnog infarkta miokarda sa ST elevacijom (STEMI) [1]. Osnovu tretmana STEMI bolesnika predstavlja, što ranije uspostavljanje protoka kroz infarktni krvni sud, kako bi se smanjila nekroza miokarda, odnosno veličina infarktnog područja. Ovo se može ostvari na dva načina: invazivno, primarnom perkutanom koronarnom intervencijom (pPCI) ili konzervativno, ordiniranjem fibrinolitičke terapije. Pacijenti kod kojih je prema anamnestičkim podacima prošlo više od $12 \mathrm{~h}$ od početka simptoma, se smatraju kasnim prezenterima bolesti, i oni čine od $8,5 \%$ do $40 \%$ svih STEMI bolesnika. Podaci o tretmanu ovih pacijenata u literaturi su oskudni i često kontraverzni. Nakon 12 sati od početka tegoba, prema važećim preporukama, pPCI strategija je indikovana, kod pacijenata čija simptomatologija ukazuje na ishemiju miokarda, hemodinamsku nestabilnost ili životno ugrožavajuće aritmije (Klasa I, nivo dokaza C) [2]. Kod bolesnika koji su stabilni i bez tegoba pPCI se može razmotriti u periodu od $12 \mathrm{~h}$ do 48 sati od početka tegoba (Klasa IIa, nivo dokaza B) [2].

\section{CILJ RADA}

Prikazati ishod lečenja pacijenata sa akutnim STEMI kod kojih je od početka tegoba prošlo više od 12 sati, a manje od $48 \mathrm{~h}$ u odnosu na tretman. Posmatraće se intrahospitalni mortalitet, jednogodišnji mortalitet i vrednost istisne frakcije leve komore.

\section{METOD RADA}

$\mathrm{U}$ istraživanje je uključeno 130 STEMI pacijenata, kod kojih je od početka tegoba prošlo više od $12 \mathrm{~h}$, a manje od $48 \mathrm{~h}$, i koji su u periodu od januara do decembra 2017. godine lečeni u Institutu za kardiovaskularne bolesti Vojvodine. 
Od ukupnog broja, kod 109 pacijenata je indikovana pPCI strategija, dok je kod dvadesetjednog pacijenta primenjen konzervativni tretman. Odluku o načinu lečenja, je donosio lekar na osnovu kliničke slike, hemodinamskog statusa, ehokardiografskog nalaza i elektrokardiografskig zapisa.

$\mathrm{Za}$ svakog pacijenta evidentirani su sledeći parametri: pol, godine starosti, telesna masa, telesna visina, indeks telesne mase i ejekciona frakcija (EF) leve komore određena tokom hospitalizacije. Evidentirani su i faktori rizika za ishemijsku bolest srca: arterijska hipertenzija, hiperlipidemija, dijabetes melitus, pušački status, gojaznost i hereditet. Izdvojeni su i značajni komorbiditeti kao što su: ranije preležani infarkt miokarda, cerebrovaskularni inzult, hirurška revaskularizacija miokarda kao i anemija, hronična bubrežna insuficijencija, periferna arterijska okluzivnu bolest i hronična opstruktvnu bolest pluća.

Potom je izvršena korelacija između ishoda lečenja, intrahospitalnog mortaliteta i jednogodišnjeg preživljavanja u odnosu na tretman, navedene faktore rizika i komorbiditete.

Podaci su obrađeni u IBM SPSS programu za statističku obradu podataka (Statistical Package for
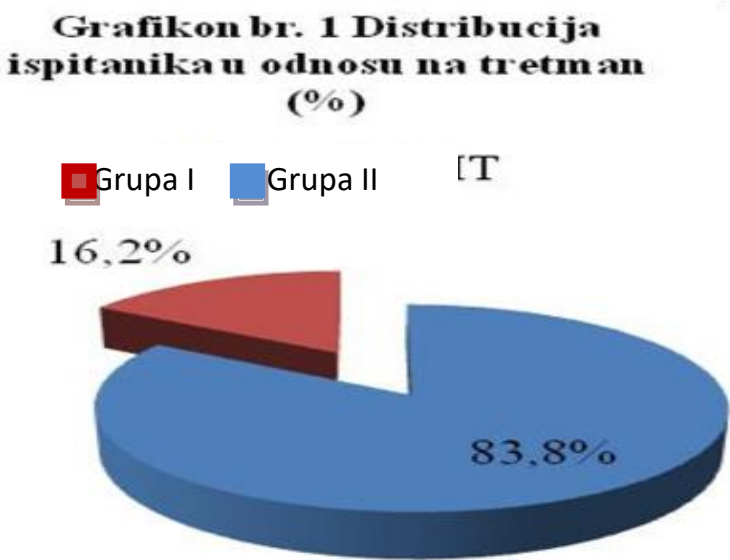

Social Sciences), verzija 23. Za analizu podataka su korišćene metode deskriptivne i inferencijalne statistike. Numeričke varijable su prikazane putem aritmetičke sredine i standardne devijacije, a kategorijske varijable putem frekvencija i procenata. Za utvrđivanje postojanja razlike varijabli između studijskih grupa korišćen je Studentov t-test i Hi kvadrat test. Postojanje statistički značajne razlike prihvatano je na nivou $p<0,05$. Rezultati su prikazani tabelarno i grafički.

\section{Etika}

Studija je sprovedena u skladu sa etičkim principima Helsinške deklaracije.

\section{Rezultati}

Od ukupnog broja ispitanika $83,8 \%$ je lečeno pPCI (grupa I), a 16,2\% konzervativno (grupa II) (grafikon 1). $\mathrm{U}$ toku lečenja zabeležen je smrtni ishod kod skoro svakog desetog bolesnika (11,5\% ukupan mortalitet intrahospitalno i nakon godinu dana), dok je kod $88,5 \%$ ispitanika ishod lečenja bio pozitivan (grafikon 2).

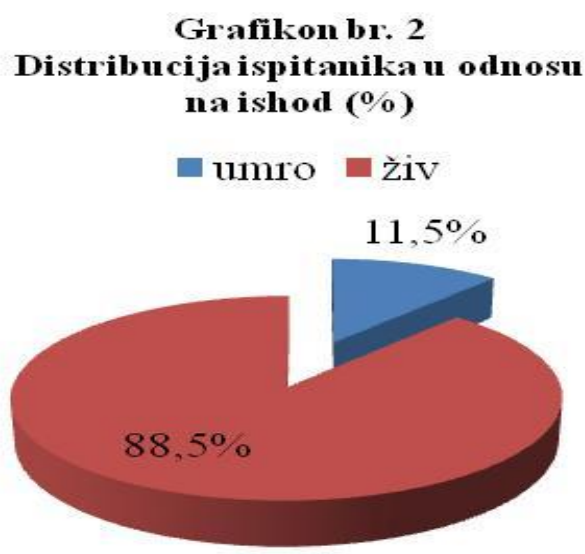

Među preminulima veći procenat pacijenata je bio iz grupe II (grafikon 3).

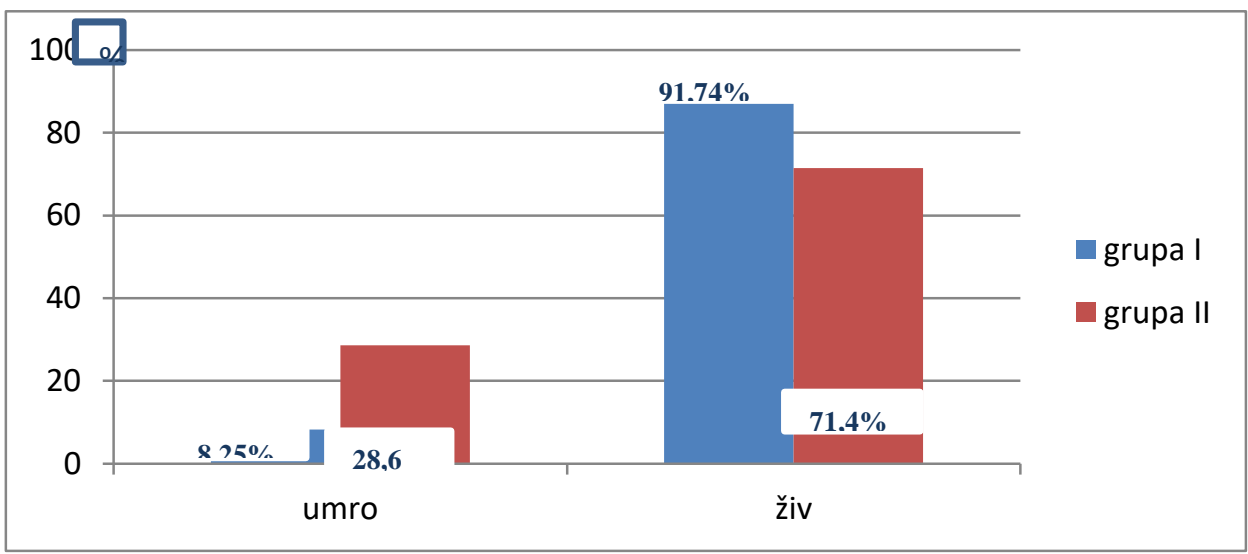

Grafikon 3. Ishod u odnosu na način tretmana

Evidentirana je statistički značajna razlika u ishodu $\mathrm{u}$ odnosu na način lečenja $\left(\mathrm{x}^{2}=7,119 ; \mathrm{p}=0,017\right)$. Letalan ishod je zabeležen kod $8,25 \%$ pacijenata u grupi I, i
$28,6 \%$ pacijenata iz grupe II. U grupi I preživelo je $91,7 \%$, a u grupi II $71,4 \%$ pacijenata. 
U grupi I postojala je statistički značajna razlika u prosečnoj starosti pacijenata, $u$ odnosu na ishod lečenja $(\mathrm{p}=0,02)$. Značajno su bili stariji bolesnici koji su preminuli $(76,33 \pm 8,544)$ u odnosu na preživele $(63,52 \pm 12,809)$ (tabela 1). Postojala je statistički značajna razlika $(\mathrm{p}=0,027) \mathrm{u}$ prosečnoj starosti među pacijentima i iz grupe tretiranih konzervativno. U grupi II, takođe, češće su umirali stariji bolesnici $(79,50 \pm 8,456)$ dok je prosečna starost preživelih bila $67,07 \pm 14,499$ (tabela 1).

\section{Tabela 1. Starost u odnosu na ishod i tretman}

\begin{tabular}{|c|c|c|c|c|c|c|}
\hline \multicolumn{2}{|c|}{ Grupa pacijenata u odnosu na tretman } & Ishod & $\mathrm{N}-\%$ & $\overline{\mathbf{x}} \pm$ SD & $\mathbf{T}$ & $\mathbf{P}$ \\
\hline \multirow{2}{*}{ Grupa I } & \multirow{2}{*}{ Starost pacijenta } & Živ & $100-91,7$ & $63,52 \pm 12,809$ & \multirow{2}{*}{$-4,103$} & \multirow{2}{*}{0,002} \\
\hline & & Umro & $9-8,3$ & $76,33 \pm 8,544$ & & \\
\hline \multirow{2}{*}{ Grupa II } & \multirow{2}{*}{ Starost pacijenta } & Živ & $15-71,4$ & $67,07 \pm 14,499$ & \multirow{2}{*}{$-2,442$} & \multirow{2}{*}{$\mathbf{0 , 0 2 7}$} \\
\hline & & Umro & $6-28,6$ & $79,50 \pm 8,456$ & & \\
\hline
\end{tabular}

Iako je u grupi I, verifikovan veći letalitet kod muškaraca, a u grupi II podjednaka smrtnost za oba pola,

nije utvrđena statistički značajna razlika, u odnosu na ishod lečenja prema polnoj pripadnosti (tabela 2).

\begin{tabular}{|c|c|c|c|c|c|c|}
\hline \multicolumn{7}{|c|}{ Tabela 2.Pol pacijenta u odnosu na ishod i tretman } \\
\hline \multirow{2}{*}{\multicolumn{3}{|c|}{ Grupa pacijenata u odnosu na tretman }} & \multicolumn{2}{|c|}{ Ishod (n - \%) } & \multirow{2}{*}{$\mathbf{X}^{2}$} & \multirow{2}{*}{$\mathbf{P}$} \\
\hline & & & Umro & Živ & & \\
\hline \multirow{2}{*}{ Grupa I } & \multirow{2}{*}{ Pol } & \multirow{2}{*}{$\begin{array}{l}\text { muški } \\
\text { ženski }\end{array}$} & $6-66,7$ & $38-38,0$ & \multirow{2}{*}{2,819} & \multirow{2}{*}{0,094} \\
\hline & & & $3-33,3$ & $62-62,0$ & & \\
\hline \multirow{2}{*}{ Grupa II } & \multirow{2}{*}{ Pol } & muški & $3-50,0$ & $5-33,3$ & \multirow{2}{*}{0,505} & \multirow{2}{*}{0,410} \\
\hline & & ženski & $3-50,0$ & $10-66,7$ & & \\
\hline
\end{tabular}

Ejekciona frakcija (EF) kod obe grupe ispitanika, je u proseku bila veća kod ispitanika koji su preživeli, ali bez statističke značajnosti (tabela 3). Tabela 4 prikazuje ishod lečenja u odnosu na faktore rizika.

\begin{tabular}{|c|c|c|c|c|c|c|}
\hline \multicolumn{7}{|c|}{ Tabela 3. EF u odnosu na tretman i ishod lečenja } \\
\hline Grup: & osu na & Ishod & $\mathrm{N}-\%$ & $\overline{\mathbf{x}} \pm \mathrm{SD}$ & $\mathbf{T}$ & $\mathbf{P}$ \\
\hline \multirow{2}{*}{ Grupa I } & \multirow{2}{*}{$\mathbf{E F}$} & Živ & $100-91,7$ & $48,143 \pm 8,1582$ & \multirow{2}{*}{1,458} & \multirow{2}{*}{0,148} \\
\hline & & Umro & $9-8,3$ & $42,600 \pm 11,0815$ & & \\
\hline \multirow{2}{*}{ Grupa II } & \multirow{2}{*}{$\mathbf{E F}$} & $\check{\text { Živ }}$ & $15-71,4$ & $44,533 \pm 14,7157$ & \multirow{2}{*}{0,933} & \multirow{2}{*}{0,362} \\
\hline & & Umro & $6-28,6$ & $37,833 \pm 15,2763$ & & \\
\hline
\end{tabular}

EF- ejekciona frakcija leve komore

Tabela 4. Faktori rizika u odnosu na ishod i lečenje

\begin{tabular}{|c|c|c|c|c|c|c|}
\hline \multicolumn{7}{|c|}{ Tabela 4. Faktori rizika u odnosu na ishod i lečenje } \\
\hline \multirow{2}{*}{\multicolumn{3}{|c|}{ Grupa pacijenata u odnosu na tretman }} & \multicolumn{2}{|c|}{ Ishod (N - \%) } & \multirow{4}{*}{$\begin{array}{c}\mathbf{X}^{2} \\
0,776\end{array}$} & \multirow{4}{*}{$\begin{array}{c}\mathbf{P} \\
0,342\end{array}$} \\
\hline & & & \multirow{3}{*}{\begin{tabular}{|c|} 
Umro \\
$1-11,1$ \\
$8-88,9$
\end{tabular}} & \multirow{3}{*}{$\begin{array}{c}\check{\mathbf{Z}} \mathbf{i v} \\
24-24,0 \\
76-76.0\end{array}$} & & \\
\hline & & $\mathrm{Ne}$ & & & & \\
\hline Grupa I & Hipertenzija & Da & & & & \\
\hline \multirow{2}{*}{ Grupa II } & \multirow{2}{*}{ Hipertenzija } & $\mathrm{Ne}$ & $0-0$ & $4-26,7$ & \multirow{2}{*}{1,976} & \multirow{2}{*}{0,228} \\
\hline & & Da & $6-100$ & $11-73,3$ & & \\
\hline \multirow{2}{*}{ Grupa I } & \multirow{2}{*}{ Pušenje } & $\mathrm{Ne}$ & $9-100$ & $66-66$ & \multirow{2}{*}{4,447} & \multirow{2}{*}{$\mathbf{0 , 0 2 9}$} \\
\hline & & Da & $0-0$ & $34-34$ & & \\
\hline \multirow{2}{*}{ Grupa II } & \multirow{2}{*}{ Pušenje } & $\mathrm{Ne}$ & $6-100$ & $9-60$ & \multirow{2}{*}{3,360} & \multirow{2}{*}{0,092} \\
\hline & & Da & $0-0$ & $6-40$ & & \\
\hline \multirow{2}{*}{ Grupa I } & \multirow{2}{*}{ Hiperlipoproteinemija } & $\mathrm{Ne}$ & $0-0$ & $32-32$ & \multirow{2}{*}{16,270} & \multirow{2}{*}{$\mathbf{0 , 0 0 0}$} \\
\hline & & Da & $9-100$ & $68-68$ & & \\
\hline \multirow{2}{*}{ Grupa II } & \multirow{2}{*}{ Hiperlipoproteinemija } & $\mathrm{Ne}$ & $2-33,3$ & $8-53,3$ & \multirow{2}{*}{0,687} & \multirow{2}{*}{0,367} \\
\hline & & Da & $4-66,7$ & $7-46,7$ & & \\
\hline \multirow{2}{*}{ Grupa I } & \multirow{2}{*}{ Diabetes Mellitus } & $\mathrm{Ne}$ & $2-22,2$ & $72-72$ & \multirow{2}{*}{9,385} & \multirow{2}{*}{0,005} \\
\hline & & Da & $7-77,8$ & $28-28$ & & \\
\hline \multirow{2}{*}{ Grupa II } & \multirow{2}{*}{ Diabetes Mellitus } & $\mathrm{Ne}$ & $2-33,3$ & $12-80$ & \multirow{2}{*}{4,200} & 0064 \\
\hline & & Da & $4-66,7$ & $3-20$ & & 0,064 \\
\hline & & $\mathrm{Ne}$ & $7-77,8$ & $79-79$ & & \\
\hline Grupa I & Hereditet & Da & $2-22,2$ & $21-21$ & 0,007 & 0,606 \\
\hline & & $\mathrm{Ne}$ & $6-100$ & $8-53,3$ & 4200 & \\
\hline Grupa II & Hereditet & Da & $0-0$ & $7-46,7$ & 4,200 & 0,055 \\
\hline
\end{tabular}


Hipertenzija kao jedan od faktora rizika, je bila zastupljena od 73,3 \% (grupa II) do 76\% (grupa I), među preživelima, dok je među preminulima u grupi I bilo $88,9 \%$ a u grupi II $100 \%$ hipertoničara, ali bez statistički značajne razlike $u$ ishodu lečenja $(\mathrm{p}=0,342)$.

Posmatrajući pušenje kao faktor rizika, svi preminuli pacijenti u obe grupe su bili nepušači, dok je među preživelima u grupi I bilo $34 \%$, a u grupi II $40 \%$ pušača sa verifikovanom statistički značajnom razlikom $(\mathrm{t}=4,447 ; \mathrm{p}=0,029) \mathrm{u}$ ishodu lečenja.
Statistički značajna razlika $(\mathrm{t}=16,270 ; \mathrm{p}<0,005)$ je takođe utvrđena $u$ ishodu lečenja pacijenata sa pozitivnom porodičnom anamnezom $(\mathrm{t}=4,200 ; \mathrm{p}=0,055)$, kao i onih koji su imali hiperlipoproteinemiju $(t=9,385$; $\mathrm{p}=0,005)$ i dijabetes melitus kao faktore rizika.

Tabela 5 prezentuje distribuciju komorbiditeta bolesnika u odnosu na način i ishod lečenja. Nijedan od komorbiditeta nije pokazao statistički značajnu razliku u distribuciji između grupa, u odnosu na ishod lečenja.

\begin{tabular}{|c|c|c|c|c|c|c|}
\hline \multicolumn{7}{|c|}{ Tabela 5. Komorbiditeti u odnosu na ishod i lečenje } \\
\hline \multirow{2}{*}{\multicolumn{3}{|c|}{ Grupa pacijenata u odnosu na tretman }} & \multicolumn{2}{|c|}{ Ishod (N - \%) } & \multirow{4}{*}{$\begin{array}{c}\mathbf{X}^{\mathbf{2}} \\
0,091\end{array}$} & \multirow{4}{*}{$\begin{array}{c}\mathbf{P} \\
0,917\end{array}$} \\
\hline & & & \multirow{3}{*}{$\begin{array}{c}\text { Umro } \\
9-100 \\
0-0\end{array}$} & \multirow{3}{*}{$\begin{array}{c}\text { Živ } \\
99-99 \\
1-1 \\
\end{array}$} & & \\
\hline & & $\mathrm{Ne}$ & & & & \\
\hline Grupa 1 & НОВР & Da & & & & \\
\hline \multirow{2}{*}{ Grupa II } & \multirow{2}{*}{ HOBP } & $\mathrm{Ne}$ & $6-100 \%$ & $15-100$ & \multirow{2}{*}{ I } & \multirow{2}{*}{ I } \\
\hline & & Da & $0-0 \%$ & $0-0$ & & \\
\hline \multirow{2}{*}{ Grupa I } & \multirow{2}{*}{ Bubrežna slabost } & $\mathrm{Ne}$ & $9-100$ & $99-99$ & \multirow{2}{*}{0,091} & \multirow{2}{*}{0,917} \\
\hline & & Da & $0-0$ & $1-6,7$ & & \\
\hline \multirow{2}{*}{ Grupa II } & \multirow{2}{*}{ Bubrežna slabost } & $\mathrm{Ne}$ & $6-100$ & $14-93,3$ & \multirow{2}{*}{0,420} & \multirow{2}{*}{0,714} \\
\hline & & Da & $0-0$ & $1-6,7$ & & \\
\hline \multirow{2}{*}{ Grupa I } & \multirow{2}{*}{ Anemija } & $\mathrm{Ne}$ & $9-100$ & $99-99$ & \multirow{2}{*}{0,091} & \multirow{2}{*}{0,917} \\
\hline & & Da & $0-0$ & $1-1$ & & \\
\hline \multirow{2}{*}{ Grupa II } & \multirow{2}{*}{ Anemija } & $\mathrm{Ne}$ & $5-83,3$ & $15-100$ & \multirow{2}{*}{2,625} & \multirow{2}{*}{0,286} \\
\hline & & Da & $1-16,7$ & $0-0$ & & \\
\hline \multirow{2}{*}{ Grupa I } & \multirow{2}{*}{ Raniji CVI } & $\mathrm{Ne}$ & $8-88,9$ & $92-92$ & \multirow{2}{*}{0,106} & \multirow{2}{*}{0,554} \\
\hline & & Da & $1-11,1$ & $8-8$ & & \\
\hline \multirow{2}{*}{ Grupa II } & Raniii CVI & $\mathrm{Ne}$ & $6-100$ & $14-93,3$ & 0420 & 0714 \\
\hline & Kanijic Vi & Da & $0-0$ & $1-6,7$ & $0,4 \angle 0$ & 0,114 \\
\hline & & $\mathrm{Ne}$ & $9-100$ & $95-95$ & & \\
\hline Grupa 1 & Infarkt miokarda & Da & $0-0$ & $5-5$ & $0,4 / 2$ & 0,644 \\
\hline Grupa U & & $\mathrm{Ne}$ & $6-100$ & $14-93,3$ & & \\
\hline Grupa II & Intarkt mokarda & Da & $0-0$ & $1-6,7$ & $0,4 \angle 0$ & $0, / 14$ \\
\hline Gruna I & Raniii CABG & $\mathrm{Ne}$ & $9-100$ & $99-99$ & 0.091 & 0.917 \\
\hline Grupa 1 & KanIJI CABG & Da & $0-0$ & $1-1$ & 0,091 & 0,91 \\
\hline Gruna II & Raniii CABG & $\mathrm{Ne}$ & $6-100$ & $14-93,3$ & 0420 & 0714 \\
\hline Grupa il & RAIIII CABG & Da & $0-0$ & $1-6,7$ & $0,4 \angle 0$ & 0,114 \\
\hline
\end{tabular}

HOBP-hronična obstruktivna bolest pluća, CVI- cerebrovaskularni insult, CABG-koronarni arterijski bypass graft

Praćenjem intrahospitalnog mortaliteta, nije detektovana statistički značajna razlika u odnosu na način lečenja. Statistički značajna razlika je uočena $u$ jednogodišnjem preživljavanju u odnosu na tretman $\left(\mathrm{x}^{2}=\right.$ $7,119 ; p=0,017)($ tabela 6).

\begin{tabular}{|c|c|c|c|c|c|c|}
\hline \multicolumn{4}{|c|}{ Tabela 6. Intrahospitalni mortalitet i jednogodišnje preživljavanje u odnosu na tretman } & & $X^{2}$ & \\
\hline & & Grupa I & Grupa II & Total & $X^{2}$ & $\mathrm{P}$ \\
\hline \multirow{2}{*}{$\begin{array}{l}\text { Intrahospitalni } \\
\text { mortalitet }\end{array}$} & $\mathrm{Ne}$ & $100-91,1$ & $17-81$ & 117 & 2,278 & \multirow{2}{*}{0.131} \\
\hline & Da & $9-8,3$ & $4-19$ & 13 & & \\
\hline \multirow{2}{*}{$\begin{array}{l}\text { Jednogodišnje } \\
\text { prezivljavanje }\end{array}$} & Živ & $100-91,7$ & $15-71,4$ & 115 & 7,119 & $\mathbf{0 , 0 1 7}$ \\
\hline & Umro & $9-8,3$ & $6-28,6$ & 15 & & \\
\hline
\end{tabular}

\section{DISKUSIJA}

Kasni STEMI prezenteri, imaju lošiju prognozu i veći rizik od nastanka komplikacija, u odnosu na pacijente kojima je pPCI urađena, unutar $12 \mathrm{~h}$ od početka simptoma. Prema aktuelnim vodičima dobre kliničke prakse, još uvek nema jasnih preporuka o tretmanu ovih pacijenata. Postoji više studija koje su istraživale efikasnosti pPCI, u odnosu na konzervativni tretman ovih bolesnika, koje su pokazale različite rezultate. Jedna od njih je multicentrična, randomizovana BRAVE-2 (Beyond 12 hours Reperfusion AlternatiVe Evaluation) studija iz 2004.godine sa 365 STEMI ispitanika (prezentacija od $12-48 \mathrm{~h})$. 
Primarni zaključak je bio, da je veličina područja leve komore zahvaćena infarktom, značajno manja kod pacijenata koji su tretirani PCI u odnosu na konzervativno lečene. Sekundarni zaključak proizašao iz studije je, da su se smrtni ishod, reinfarkt miokarda i cerebrovaskularni inzult, češce javljali kod pacijenata tretiranih konzervativno $(6,6 \%$ vs $4,4 \%)$ [4].

Ndrepepa i saradnici [5] su u istraživanju (maj 2001. - decembar 2004.) na 365 kasnih STEMI prezentera (12-48h), zaključili da je kod PCI lečenih pacijenata značajno redukovan četvorogodišnji mortalitet. Iako je naša studija bila vremenski kraća i sprovedena na 130 pacijenata, takođe je registrovana statistički značajna razlika u jednogodišnjem preživljavanju u odnosu na tretman (83,8\% PCI i 16,2\% konzervativno) (tabela 6).

Poljski registar za akutni koronarni sindrom, je prateći mortalitet kod kasnih STEMI prezentera obe grupe, na uzorku od 2.036 pacijenata, dokazao signifikantno manji jednogodišnji mortalitet, $\mathrm{u}$ grupi tretiranih PCI metodom $(9,3 \%$ vs $17,9 \%$; $p<0,0001)[6]$.

Za razliku od naše u Occluded Artery Trial (OAT studiji), kasnim STEMI prezenterima, smatrani su oni bolesnici koji su se javili od 3-28 dana od početka simptoma. Četvorogodišnjim praćenjem ovih pacijenta, utvrđeno je da PCI, nije bila superiornija metoda lečenja, ni u smanjivanju mortaliteta, niti u povećanju ejekcione frakcije leve komore [7,8]. Ovi rezultati su saglasni sa onima iz naše studije, iako je definicija kasnih prezentera bila drugačija. U različitim meta analizama (Ioannidis [9]; Abbate [10]; Yang [11]), na različitom broju ispitanika, su kasnim prezenterima smatrani STEMI pacijenti, koji su se javili u bolnicu u periodu od 1-45 dana (Ioannidis i sar.) ili 12h-60dana (Abbate i sar.; Yang i sar.). Ioannidis i saradnici doneose zaključak da je u grupi pacijenata lečenih PCI metodom, ejekciona frakcija leve komore bila lako povišena, ali bez statističke značajnosti. Meta analiza Abbate-a i saradnika je pokazala, da je u PCI grupi značajno poboljšana funkcija miokarda, kao i preživljavanje, a u meta analizi Yang-a i saradnika da je u PCI grupi signifikantno manji mortalitet, broj neželjenih kardiovaskularnih (MACE) događaja, kao i srčana slabost. Subanaliza Yang-a i saradnika je utvrdila ovaj benefit, samo kod bolesnika kojima je PCI urađena u periodu od 12 sata do 48 sati.

Sa odlaganjem javljanja STEMI pacijenata lekaru, što su pokazale i prve eksperimentalne studije, nastaju hemoragije unutar infarktnog dela miokarda, u okolnostima produžene koronarne okluzije, i kasne reperfuzije. Neželjene mehaničke komplikacije mogu dovesti do povećanja krutosti miokarda, verovatnoće rupture srca $\mathrm{i}$ odloženog procesa zarastanja/formiranja ožiljka [12]. Zbog mogućih neželjenih ishoda, poput rupture srca i cerebrovaskularnog inzulta, preporučuje se pažljiviji klinički i ehokardiografski monitoring ove populacije STEMI pacijenata.

Rezultati naše studije pokazali su, starost, hereditet, hiperlipoproteinemija, DM i pušenje, statistički značajno utiču na ishod. Među preživelima, najveći procenat čine osobe mlađeg životnog doba i ženski pol, a među umrlima starije životno doba, muški pol, hipertenzija, hiperlipoproteinemija i dijabetes melitus. Analizom rezultata Vienna STEMI registra (januar 2003. decembar 2009.) na 4.593 ispitanika, dijabetes melitus i ženski pol, su prikazani kao nezavisni prediktori kasne prezentacije akutnog STEMI [3], što proizilazi i iz naše studije.

U JAC registru (Jacarta Acute Coronary Syndrome registar) sa 1.187 STEMI pacijenata i više od 12 sati od početka tegoba, za razliku od naše studije i Vienna STEMI registra sa predominaciom ženskog pola, 85\% pacijenata su bili muškarci [13], a kao najčešći faktori rizika su izdvojeni pušački staž $(62 \%)$ i hipertenzija (54\%)[13].

Hipertenzija kao faktor rizika, među našim ispitanicima, bila je zastupljena sa $76 \%$ kod preživelih i $88,9 \%$ preminulih u grupi I dok su u grupi II svi preminuli kao i većina preživelih takođe $(73,3 \%)$ imali hipertenziju.

Praćenjem pušenja kao faktorom rizika došli smo do sledećih rezultata: $\mathrm{u}$ obe grupe, nijedan preminuli pacijent nije bio pušač, dok je među preživelima, $34 \%$ u grupi I, i $40 \%$ pacijenata a u grupi II bili pušači. Uočena je statistički značajna razlika $(\mathrm{t}=4,447 ; \mathrm{p}=0,029) \mathrm{u}$ pogledu ishoda lečenja i pušenja kao faktora rizika.

Praćeni komorbiditeti (raniji infarkt miokarda, ili hirurška revaskularizacija miokarda), nisu pokazali statistički značajnu razliku u odnosu na način lečenja. $\mathrm{Na}$ osnovu iznetog, se može pretpostaviti da pacijenti koji su ranije preboleli infarkt miokarda, kao i oni sa prethodnom revaskularizacijom miokarda, znaju da prepoznaju simptome akutnog infarkta miokarda i blagovremeno zatraže lekarsku pomoć.

Iako su mnogi aspekti zbrinjavanja kasnih STEMI prezentera, još uvek predmet brojnih debata i istraživanja, prema aktuelnim preporukama strategija pPCI (Klasa I, nivo dokaza C) je indikovana, kod pacijenata sa kliničkim i/ili elektrokardiografskim dokazom aktuelne ishemije, hemodinamske nestabilnosti ili životno ugrožavajućih aritmija [2]. Rutinska pPCI strategija se može razmotriti kod STEMI pacijenata koji su se kasno javili (12-48h) od početka simptoma (Klasa IIa, nivo dokaza B) [2]. Pri donošenju odluke o tretmanu ovih bolesnika, u obzir bi trebalo uzeti i intermitentnu, ili delimičnu okluziju koronarne arterije, stepen kolateralne cirkulacije, ishemijsko prekondicioniranje i metabolički status unutar područja ishemije. Sve ovo su faktori od značaja kada je u pitanju planiranje adekvatnog tretmana ovih pacijenata [15].

\section{Zaključak}

Obzirom da nema jasnih preporuka o tretmanu ovih bolesnika nameće se potreba za novim randomizovanim studijama.

Sukob interesa: Autori izjavljuju da ne postoji sukob interesa.

\section{Literatura:}

1. Hartley A, Marshall D, Salciccioli J, Sikkel M, Maruthappu M, Shalhoub J. Trends in mortality from Ishemic Heart Disease and Cerebrovascular Disease 
in Europe 1980 to 2009.Circulation.2016;133:19161926.

Doi: 10.1161/CIRCULATIONAHA.115.018931.

2. Ibanez B, James S, Agewall S, Antunes M, Bucciarelli-Ducci C, Bueno H.2017 ESC Guidelines for the Management of Acute Myocardial Infarction in Patients Presenting With ST-segment Elevation: The Task Force for the Management of Acute Myocardial Infarction in Patients Presenting With ST-segment Elevation of the European Society of Cardiology (ESC). Eur Heart J. 2018;39(2):119-177. PMID: 28886621.doi: 10.1093/eurheartj/ehx393.

3. Jäger B, Farhan S, Rohla M, Christ G, PodczeckSchweighofer A, Schreiber W, et al. Vienna STEMI Registry Group.Clinical predictors of patient related delay in the VIENNA ST-elevation myocardial infarction network and impact on long-term mortality. Eur Heart J Acute Cardiovasc Care. 2017;6(3):254261.

PMID: 26888787.DOI: 10.1177/2048872616633882.

4. Schömig A, Mehilli J, Antoniucci D, Ndrepepa G, Markwardt C, Di Pede F, et al. Mechanical reperfusion in patients with acute myocardial infarction presenting more than 12 hours from symptom onset: a randomized controlled trial. JAMA. 2005;293(23):2865-2872.

PMID: 15956631.DOI: 10.1001/jama.293.23.2865.

5. Ndrepepa G, Kastrati A, Mehilli J, Antoniucci D, Schomig A. Mechanical reperfusion and long-term mortality in patients with acute myocardial infarction presenting 12 to 48 hours from onset of symptoms. JAMA. 2009; 301(5): 487-488. PMID: 19190313. DOI: $10.1001 /$ jama.2009.32,

6. Gierlotka M, Gasior M, Wilczek K, Hawranek M, Szkodzinski J, Paczek P, et al. Reperfusion by primary percutaneous coronary intervention in patients with ST-segment elevation myocardial infarction within 12 to 24 hours of the onset of symptoms (from a prospective national observational study [PL-ACS]). Am J Cardiol. 2011; 107(4):501-508. PMID: 21195380.DOI: 10.1016/j.amjcard.2010.10.00 8.

7. Jia-Wei Wu, Hao Hu, Dan Li, and Li-Kun Ma. Inhospital outcomes of delayed stenting in hemodynamically stable patients with ST-segment elevation myocardial infarction: the CCC (Care for Cardiovascular Disease in China) project. Cardiovasc Diagn Ther. 2019; 9(5): 462-471. DOI: 10.21037/ cdt.2019.08.10. PMID 31737517
8. Hochman JS, Lamas GA, Buller CE, Dzavik V, Reynolds HR, Abramsky SJ, et al. Occluded Artery Trial Investigators. Coronary intervention for persistent occlusion after myocardial infarction. N Engl J Med. 2006; 355(23): 2395-2407. PMID: 17105759. doi: 10.1056/NEJMoa066139.

9. Ioannidis JP, Katritsis DG. Percutaneous coronary intervention for late reperfusion after myocardial infarction in stable patients. Am Heart J. 2007; 154(6): 1065-1071. PMID: 18035076. DOI: 10.1016/ j.ahj.2007.07.049.

10. Biondi GZ, Abbate A, Benedetto U, Palmerini T, D'Ascenzo, Frati G. Network meta-analysis for evidence synthesis: What is it and why is it posed to dominate cardiovascular decision making? International Journal of Cardiology. 2015;182:309314. PMID: 25585376. Doi: 10.1016/ j.ijcard.2015.01.023.

11. Yang HT, Xiu WJ, Zheng YY, Liu F, Gao Y, Ma X, et al. Invasive reperfusion after 12 hours of the symptom onset remains beneficial in patients with STsegment elevation myocardial infarction: Evidence from a meta-analysis of published data. Cardiol J. 2019; 26: 333-342. PMID: 29611165. DOI: 10.5603/ CJ.a2018.0034.

12. Betgem R, Waard D, Guus A, Nijveldt R, Beek A, Javier $\mathrm{E}$, et al. Intramyocardial haemorrhage after acute myocardial infarction. Nature Reviews. Cardiology. 2015; 12(3):156-167. Doi: 10.1038/ nrcardio.2014.188. PMID: 25403783

13. Dharma S, Andriantoro H, Purnawan I, Dakota I, Basalamah F, Hartono B, et al. Characteristics, treatment and in-hospital outcomes of patients with STEMI in a metropolitan area of a developing country: an initial report of the extended Jakarta Acute Coronary Syndrome registry. BMJ Open. 2016; 6(8): e012193. PMID: 27580835. doi: 10.1136/bmjopen2016-012193.

14. Cerrato E, Forno D, Ferro S, Chinaglia A. Characteristics, in-hospital management and outcome of late acute ST-elevation myocardial infarction presenters. J Cardiovasc Med (Hagerstown). 2017; 18(8): 567-571. PMID: 28504982. DOI: $10.2459 /$ JCM.0000000000000527.

15. Guo Q, Huang J, Shen Y, Tong G, Li H, Meng $\mathrm{S}$. The role of late reperfusion in ST-segment elevation myocardial infarction: a real-world retrospective cohort study. BMC Cardiovasc Disord. 2020; 20: 207. DOI:10.1186/s12872-020-01479-0. 
ORIGINAL ARTICLE

\title{
TREATMENT OUTCOME IN PATIENTS WITH ACUTE ST ELEVATION MYOCARDIAL INFARCTION WHERE MORE THAN 12 HOURS AND LESS THAN 48 HOURS HAVE PASSED FROM THE ONSET OF SYMPTOMS
}

\author{
Vladimir IVANOVIĆl, , Jelena GRGUR ${ }^{3}$, Dragana DABOVIĆ, Milovan PETROVIĆ',2, Anastazija \\ STOJŠIĆ-MILOSAVLJEVIĆ ${ }^{1,2}$, Marija BJELOBRK ${ }^{1,2}$, Milenko ČANKOVIĆ ${ }^{1,2}$, Maja STEVANOVIĆ ${ }^{1,2}$ \\ ${ }^{1}$ Institute for cardiovascular diseades of Vojvodina, Clinic of cardiology, Sremska Kamenica, Serbia; \\ ${ }^{2}$ University of Novi Sad, Medical faculty, Novi Sad, Serbia; ${ }^{3}$ Institute for Child and Youth Health \\ Care of Vojvodina, Novi Sad, Serbia.
}

\begin{abstract}
Introduction/Objective Patients who have had symptoms for more than $12 \mathrm{~h}$ before receiving treatment are considered to be myocardial infarction late presenters. The literature contains scarce and often controversial data about treating such patients. The objective of the paper is to present treatment outcome in patients with acute STelevation myocardial infarction (STEMI), whose therapy was initiated more than $12 \mathrm{~h}$ and less than 48 hours after the onset of symptoms.

Methods The research included 130 patients who had suffered from acute STEMI in 2017, all of whom presented more than $12 \mathrm{~h}$ and less than $48 \mathrm{~h}$ after the onset of symptoms. A primary percutaneous coronary intervention (PPCI) was used to treat 109 patients, while 21 patients were treated conservatively. An analysis was performed correlating treatment results, intrahospital mortality, one-year survival rate depending on the type of treatment, risk factors and comorbidity.

Results A statistically significant difference $\left(x^{2}=7,119 ; \mathrm{p}=0,017\right)$ has been verified when comparing the mortality of STEMI patients treated with PPCI $(8.3 \%)$ and those treated conservatively $(28.6 \%)$. A statistically significant difference $(\mathrm{t}=9,385 ; \mathrm{p}=0,005)$ has been verified when it came to treating STEMI patients that were also suffering from diabetes. In the group treated with PPCI, $77.8 \%$ of the patients that had died had diabetes. No comorbidity showed a statistically significant difference in distribution depending on the type of treatment and treatment results.

Conclusion When deciding on the type of treatment these patients shall receive, the following should be taken into consideration: clinical presentation, hemodynamic status and presence of life-threatening arrhythmias. There is still no clear guideline for treating such patients.
\end{abstract}

Keywords: acute myocardial infarction, primary percutaneous coronary intervention, medical treatment, outcome 